\title{
DETERMINAÇÃO DE COMPOSTOS FENÓLICOS POR LC-MS/MS E CAPACIDADE ANTIOXIDANTE DE ACEROLA EM TRÊS ESTÁDIOS DE MATURAÇÃO COMESTÍVEIS
}

Siluana Katia Tischer Seraglio ${ }^{1}$, Mayara Schulz ${ }^{1}$, Priscila Nehring ${ }^{2}$, Fabiana Della Betta ${ }^{3}$, Andressa Camargo Valese ${ }^{1}$, Heitor Daguer ${ }^{4}$, Luciano Valdemiro Gonzaga ${ }^{5}$, Roseane $\mathrm{Fett}^{6}$, Ana Carolina Oliveira $\operatorname{Costa}^{6}$

${ }^{1}$ Universidade Federal de Santa Catarina, Departamento de Ciência e Tecnologia de Alimentos, Mestre em Ciência dos Alimentos

${ }^{2}$ Instituto Federal de Santa Catarina - Campus Canoinhas, Mestre em Ciência dos Alimentos

${ }^{3}$ Universidade Federal de Santa Catarina, Departamento de Ciência e Tecnologia de Alimentos, Doutora em Ciência dos Alimentos

${ }^{4}$ Ministério da Agricultura, Pecuária e Abastecimento, Laboratório Nacional Agropecuário - Seção Laboratorial Avançada, Doutor em Tecnologia de Alimentos

${ }^{5}$ Universidade Federal de Santa Catarina, Departamento de Ciência e Tecnologia de Alimentos, Graduando em Química

${ }^{6}$ Universidade Federal de Santa Catarina, Departamento de Ciência e Tecnologia de Alimentos, Doutora em Química

E-mail para contato: siluanaseraglio@ hotmail.com

RESUMO - Os frutos de acerola são reconhecidos principalmente por sua composição rica em vitamina $\mathrm{C}$, no entanto, estes frutos apresentam outros compostos fitoquímicos responsáveis pela sua capacidade antioxidante, entre eles os compostos fenólicos. Neste sentido, este trabalho objetivou investigar compostos fenólicos por cromatografia líquida acoplada à espectrometria de massas (LC-MS/MS) e avaliar a capacidade antioxidante em frutos de acerola em três estádios de maturação comestíveis. Foram avaliados 33 compostos fenólicos, e destes, 16 foram quantificados, sendo os compostos majoritários a quercetina, ácido cafeico, kaempferol e isoramnetina. Os resultados para a capacidade antioxidante pelo o ensaio DPPH foram de 1117,71, 1120,40 e 963,26 $\mathrm{mg}^{\text {Trolox }} \mathrm{g}^{-1}$ em matéria seca para os frutos menos maduro, maduro e completamente maduro, respectivamente; e pelo ensaio FRAP, os valores foram de 400,87, 508,24 e 341,19 $\mu$ mol Trolox $\mathrm{g}^{-1}$ em matéria seca para os frutos menos maduro, maduro e completamente maduro, respectivamente. Foi possível observar que o processo de maturação influenciou significativamente a concentração da maioria dos compostos fenólicos investigados bem como a capacidade antioxidante nos frutos de acerola, ocorrendo, de maneira geral, uma tendência de diminuição nestes teores com o avanço da maturação. No entanto, os resultados encontrados podem ser considerados expressivos sugerindo que os três estádios de maturação avaliados podem contribuir na ingestão diária de antioxidante naturais.

Palavras-chave: Malpighia emarginata DC. Compostos bioativos. Amadurecimento. 


\section{Recebido em:}

$01 / 09 / 2018$

Aceito em: $14 / 11 / 2018$

DOI: $10.5965 / 24473650412018096$

\section{INTRODUÇÃO}

A acerola (Malpighia emarginata DC.) é um fruto nativo da América do Sul e América Central, cultivado em clima tropical e subtropical (LEFFA et al., 2014). Os frutos geralmente apresentam de 1 a $4 \mathrm{~cm}$ de diâmetro e pesam entre 2 e 15 g (DELVA; SCHNEIDER, 2013a; NUNES et al., 2011), e durante a fase de desenvolvimento apresentam coloração verde e com o avanço da maturação vão adquirindo pigmentos alaranjados até por fim atingirem coloração vermelha intensa quando completamente maduros, processo que dura em média 5 dias (BARBOZA; TAVARES; MELO, 1996). Além disso, apresentam uma alta atividade metabólica pós-colheita o que os torna bastante perecíveis, especialmente para a venda in natura (DELVA; SCHNEIDER, 2013a; NUNES et al., 2011).

Os frutos de acerola são reconhecidos por apresentar composição rica em vitamina $\mathrm{C}$, sendo que o consumo de dois frutos pode atender as necessidades diárias recomendadas desta vitamina para um indivíduo adulto (IOM, 2001; TACO, 2011). Entretanto, além da vitamina C, a acerola apresenta outros compostos químicos com potencial benéfico à saúde, entre eles tiamina, riboflavina, niacina, fibras, minerais, carotenoides e os compostos fenólicos (DE ROSSO et al., 2008; MEZADRI et al., 2008). Alguns estudos tem reportado o potencial antioxidante da acerola, tanto da fruta in natura e de suco de acerola (DE ASSIS et al., 2009; LEFFA et al., 2014; RUFINO et al., 2010). Mezadri et al. (2008) avaliaram a capacidade antioxidante de frutos de acerola e seus derivados e encontraram para o suco de acerola valores de atividade antioxidante superiores a outros sucos de frutas ricas em polifenóis como morango, uva e maçã.

Os compostos fenólicos são metabólitos secundários que desempenham diversas funções nas plantas e o consumo regular de produtos ricos nestes compostos tem sido associado à redução dos riscos de câncer, obesidade, doenças cardiovasculares e outras doenças crônicas (AHMAD et al., 2016; BOEING et al., 2014). Nas frutas, o tipo e a concentração dos compostos fenólicos variam dependendo de aspectos genéticos (gênero, espécie, cultivar) bem como de acordo com as condições ambientais (clima e solo) e grau de maturação (LEE; DOSSETT; FINN, 2012). Diversas técnicas têm sido relatadas na literatura para determinação de compostos fenólicos individuais em frutas, como a cromatografia (AHMAD et al., 2016; BATAGLION et al., 2015; FAWOLE; OPARA, 2013; SERAGLIO et al., 2018) e eletroforese capilar (HURTADO-FERNANDEZ et al., 2013; MEMON et al., 2017). Dentre as técnicas citadas acima, a cromatografia líquida acoplada à espectrometria de massas tornou-se uma importante ferramenta para a identificação e quantificação de compostos fenólicos em frutas e hortaliças, principalmente devido à sua alta sensibilidade (DE LA ROSA et al., 2010).

Neste sentido, o objetivo deste trabalho foi determinar a composição de compostos fenólicos utilizando cromatografia liquida acoplada a espectrometria de massas (LC-MS/MS) e a capacidade antioxidante de frutos de acerola (Malpighia emarginata DC.) em três estádios de maturação comestíveis.

\section{MATERIAIS E MÉTODOS}

\subsection{Reagentes e soluções}




\section{Recebido em:}

$01 / 09 / 2018$

Aceito em:

$14 / 11 / 2018$

Reagentes de grau analítico (pureza $\geq 95 \%$ ) e água ultrapura (Milli-Q, Millipore, Bedford, MA, E.U.A.) foram utilizados para o preparo das soluções.

Os reagentes de grau HPLC dimetilsulfóxido, metanol e acetonitrila foram adquiridos da Merk (Darmstadt, Alemanha) enquanto o ácido fórmico de grau HPLC foi obtido da J. T. Baker (Phillipsburg, NJ, E.U.A). Os padrões dos compostos fenólicos individuais: apigenina, isoramnetina, pinobanksin, ácido ferúlico, ácido sinápico, ácido $p$-aminobenzóico, ácido $p$-cumárico, 4-metilumbeliferona, ácido vanílico, rutina, naringina, (+)-catequina, sinapaldeído, ácido cafeico, ácido clorogênico, coniferaldeído, siringaldeído, crisina, hesperidina, ácido siríngico, kaempferol, naringenina, (-)-epigalocatequina galato, (-)-epicatequina, pinocembrin, galangina, ácido salicílico, quercetina, ácido gálico, ácido benzoico, ácido 3,4-dihidroxibenzoico, isoquercitrina e luteolina foram obtidos da Sigma-Aldrich (St. Louis, MO, E.U.A).

Foram preparadas soluções estoques individuais na concentração de $1000 \mathrm{mg} \mathrm{L}^{-1}$ para cada fenólico, com exceção dos compostos isoramnetina e pinobanksin, os quais apresentaram concentrações de 1250 e $1150 \mathrm{mg} \mathrm{L}^{-1}$, respectivamente. As soluções foram preparadas em metanol, exceto para os compostos hesperidina e isoramnetina, nos quais dimetilsulfóxido foi utilizado. As soluções foram estocadas a $4 \pm 2{ }^{\circ} \mathrm{C}$. Antes das análises, uma solução intermediária, composta por todos os analitos $\left(1000 \mu \mathrm{g} \mathrm{L}^{-1}\right)$, foi preparada em metanol e utilizada para a construção da curva de calibração.

Os reagentes 2,2-difenil-1-picrildrazil (DPPH), 2,4,6-tris(2-piridil)-s-triazina (TPTZ), acetona, acetato de sódio, ácido clorídrico $(\mathrm{HCl})$, ácido cítrico, cloreto férrico e Trolox foram adquiridos da Sigma-Aldrich (St. Louis, MO, E.U.A).

\subsection{Amostra e preparo da amostra}

Frutos in natura de acerola (Malpighia emarginata DC.) foram coletados em Pinhalzinho, Santa Catarina, Brasil (latitude 26 85' 02" S, longitude 52 98' 17" W, altitude $515 \mathrm{~m}$ ), em janeiro de 2015. Os frutos foram classificados em três estádios comestíveis de maturação, nomeados como menos maduro (estádio 1), maduro (estádio 2) e completamente maduro (estádio 3). Os frutos foram coletados manualmente em uma única coleta de três plantas randomicamente selecionadas, onde apenas os frutos sem danos foram colhidos. Estes frutos foram mantidos congelados a $-18 \pm 2{ }^{\circ} \mathrm{C}$ até o momento das análises. Previamente às análises, os frutos foram descongelados e a polpa e pele manualmente separadas das sementes, que foram descartadas. A polpa e a pele foram trituradas juntas utilizando um processador de alimentos doméstico e submetidas às análises de compostos fenólicos individuais e capacidade antioxidante.

\subsection{Determinação de compostos fenólicos individuais}

\section{Extração dos compostos fenólicos conjugados}

A extração dos compostos fenólicos conjugados foi realizada de acordo com o método proposto por Schulz et al. (2015), com adaptações (SERAGLIO et al., 2018). Previamente, $1,0 \mathrm{~g}( \pm 0,1)$ de amostra triturada foi agitada manualmente com $9 \mathrm{~mL}$ de água ultrapura e $20 \mathrm{mg}$ de ácido ascórbico por $1 \mathrm{~min}$. Na sequência, $5 \mathrm{~mL}$ de $\mathrm{HCl} 6 \mathrm{~mol} \mathrm{~L}^{-1}$ foi adicionado ao sistema e este incubado a $85^{\circ} \mathrm{C}$ por 30 min em estufa. A solução foi resfriada e extraída sequencialmente por 1 min com $5 \mathrm{~mL}$ de acetato de 


\section{Recebido em:}

$01 / 09 / 2018$

Aceito em:

$14 / 11 / 2018$

etila por três vezes. Os sobrenadantes, após centrifugação por 5 min a $1338 \mathrm{~g}$, foram combinados e secos por meio da adição de $3 \mathrm{~g}$ de sulfato de sódio anidro. Na sequência, a fração líquida foi rotaevaporada e o resíduo reconstituído em $1 \mathrm{~mL}$ de metanol.

O extrato reconstituído foi diluído na proporção 1:9 (v/v) com fase móvel composta de $98 \%$ de solvente A (água com ácido fórmico $0,1 \%$ ) e $2 \%$ de solvente B (acetonitrila com ácido fórmico 0,1\%) e injetado no sistema de cromatografia líquida (SERAGLIO et al., 2018). Posteriores diluições foram realizadas quando necessário. Os resultados foram expressos em $\mathrm{mg} \mathrm{kg}^{-1} \mathrm{em}$ matéria seca.

\section{Determinação dos compostos fenólicos}

A identificação e quantificação dos compostos fenólicos individuais foi realizado de acordo com o método descrito por Seraglio et al. (2018) em um cromatógrafo líquido (Agilent Technologies, Agilent 1290 series, Wilmington, DE, E.U.A.) acoplado a um espectrômetro de massas triploquadrupolo (AB Sciex, QTRAP® 5500 system, Foster City, CA, E.U.A.) equipado com fonte de ionização por eletronebulização.

Os parâmetros operacionais do espectrômetro de massas e de validação são apresentados na Tabela 1 e Tabela 2, respectivamente.

Tabela 1 - Parâmetros do espectrômetro de massas no modo de monitoramento de reações múltiplas de compostos fenólicos.

\begin{tabular}{|c|c|c|c|c|c|c|c|}
\hline $\begin{array}{l}\text { Composto } \\
\text { fenólico }\end{array}$ & $\begin{array}{l}\text { Tempo } \\
\text { de } \\
\text { retenção } \\
\text { (min) }\end{array}$ & $\begin{array}{c}\text { Íon } \\
\text { precursor } \\
{[\mathrm{M}+\mathrm{H}]^{-}}\end{array}$ & $\begin{array}{l}\text { Fragmentos } \\
(\mathrm{m} / \mathrm{z})\end{array}$ & $\begin{array}{l}\text { DP } \\
\text { (V) }\end{array}$ & $\begin{array}{l}\mathbf{E P} \\
(\mathbf{V})\end{array}$ & $\mathrm{CE}(\mathrm{V})$ & $\begin{array}{c}\text { CXP } \\
(\mathbf{V})\end{array}$ \\
\hline \multirow{2}{*}{ Ácido cafeico } & \multirow[b]{2}{*}{4,25} & \multirow[b]{2}{*}{178,9} & $135,000^{\mathrm{a}}$ & -115.0 & -10.0 & -22.0 & -9.0 \\
\hline & & & $000^{\mathrm{b}}$ & 0 & $-10,0$ & $-30,0$ & $-7,0$ \\
\hline \multirow{2}{*}{ Crisin } & \multirow[b]{2}{*}{7,96} & \multirow{2}{*}{252,982} & $142,900^{\mathrm{a}}$ & $-170,0$ & $-10,0$ & $-36,0$ & $-9,0$ \\
\hline & & & $209,100^{b}$ & $-170,0$ & $-10,0$ & $-30,0$ & $-11,0$ \\
\hline \multirow{2}{*}{ Coniferaldeído } & \multirow{2}{*}{5,71} & \multirow{2}{*}{176,978} & $134,000^{\mathrm{a}}$ & $-30,0$ & $-10,0$ & $-28,0$ & $-9,0$ \\
\hline & & & 160,8 & $-30,0$ & $-10,0$ & $-28,0$ & $-11,0$ \\
\hline \multirow{2}{*}{ Ácido $p$-cumárico } & \multirow{2}{*}{4,99} & \multirow{2}{*}{162,921} & $119,000^{\mathrm{a}}$ & $-90,0$ & $-10,0$ & $-20,0$ & $-7,0$ \\
\hline & & & $93,000^{\mathrm{b}}$ & $-90,0$ & $-10,0$ & $-40,0$ & $-5,0$ \\
\hline \multirow{2}{*}{$\begin{array}{l}\text { Ácido 3,4- } \\
\text { dihidroxibenzóico }\end{array}$} & \multirow{2}{*}{3,18} & \multirow{2}{*}{152,901} & $109,000^{\mathrm{a}}$ & $-75,0$ & $-10,0$ & $-20,0$ & $-7,0$ \\
\hline & & & & $-75,0$ & $-10,0$ & $-32,0$ & $-13,0$ \\
\hline \multirow{2}{*}{$\begin{array}{l}(-)- \\
\text { Epigalocatequina } \\
\text { galato }\end{array}$} & \multirow[b]{2}{*}{4,33} & \multirow[b]{2}{*}{$456,9^{\circ}$} & $169,000^{\mathrm{a}}$ & $-165,0$ & $-10,0$ & $-20,0$ & $-11,0$ \\
\hline & & & $125,000^{b}$ & $-165,0$ & $-10,0$ & $-52,0$ & $-9,0$ \\
\hline \multirow{2}{*}{ Ácido gálico } & \multirow{2}{*}{2,32} & \multirow{2}{*}{168,894} & $124,900^{\mathrm{a}}$ & $-110,0$ & $-10,0$ & $-20,0$ & $-7,0$ \\
\hline & & & $79,000^{\mathrm{b}}$ & $-110,0$ & $-10,0$ & $-30,0$ & $-11,0$ \\
\hline \multirow{2}{*}{ Isoramnetina } & \multirow{2}{*}{6,92} & \multirow{2}{*}{315,008} & $300,000^{\mathrm{a}}$ & $-225,0$ & $-10,0$ & $-28,0$ & $-15,0$ \\
\hline & & & & & $-10,0$ & $-38,0$ & $-9,0$ \\
\hline \multirow{2}{*}{ Isoquercitrina } & \multirow{2}{*}{5,00} & \multirow{2}{*}{462,980} & $300,000^{\mathrm{a}}$ & $-215,0$ & $-10,0$ & $-36,0$ & $-15,0$ \\
\hline & & & 271,000 & $-215,0$ & $-10,0$ & $-56,0$ & $-13,0$ \\
\hline
\end{tabular}


Recebido em:

01/09/2018

Aceito em:

14/11/2018

\begin{tabular}{|c|c|c|c|c|c|c|c|}
\hline \multirow{2}{*}{$\begin{array}{l}4- \\
\text { Metilumbeliferona }\end{array}$} & \multirow{2}{*}{5,78} & \multirow{2}{*}{174,895} & $133,000^{\mathrm{a}}$ & $-135,0$ & $-10,0$ & $-28,0$ & $-9,0$ \\
\hline & & & $119,100^{\mathrm{b}}$ & $-135,0$ & $-10,0$ & $-36,0$ & $-7,0$ \\
\hline \multirow{2}{*}{ Naringenina } & \multirow{2}{*}{6,80} & \multirow{2}{*}{271,012} & $151,000^{\mathrm{a}}$ & $-130,0$ & $-10,0$ & $-24,0$ & $-25,0$ \\
\hline & & & $119,000^{b}$ & $-130,0$ & $-10,0$ & $-34,0$ & $-11,0$ \\
\hline \multirow{2}{*}{ Naringina } & \multirow{2}{*}{5,32} & \multirow{2}{*}{579,017} & $271,000^{\mathrm{a}}$ & $-255,0$ & $-10,0$ & $-42,0$ & $-13,0$ \\
\hline & & & $151,000^{b}$ & $-255,0$ & $-10,0$ & $-48,0$ & $-9,0$ \\
\hline \multirow{2}{*}{ Pinobanksin } & \multirow{2}{*}{6,83} & \multirow{2}{*}{270,967} & $150,900^{\mathrm{a}}$ & $-140,0$ & $-10,0$ & $-24,0$ & $-9,0$ \\
\hline & & & $119,500^{\mathrm{b}}$ & $-140,0$ & $-10,0$ & $-32,0$ & $-7,0$ \\
\hline \multirow{2}{*}{ Quercetina } & \multirow{2}{*}{6,29} & \multirow{2}{*}{301,002} & $150,900^{\mathrm{a}}$ & $-50,0$ & $-10,0$ & $-28,0$ & $-9,0$ \\
\hline & & & $121,000^{\mathrm{b}}$ & $-50,0$ & $-10,0$ & $-34,0$ & $-7,0$ \\
\hline \multirow{2}{*}{ Rutina } & \multirow{2}{*}{4,82} & \multirow{2}{*}{609,004} & $299,900^{\text {a }}$ & $-230,0$ & $-10,0$ & $-48,0$ & $-15,0$ \\
\hline & & & $270,900^{\mathrm{b}}$ & $-230,0$ & $-10,0$ & $-70,0$ & $-9,0$ \\
\hline \multirow{2}{*}{ Ácido salicílico } & & \multirow{2}{*}{136,943} & $93,100^{\mathrm{a}}$ & $-15,0$ & $-10,0$ & $-22,0$ & $-5,0$ \\
\hline & & & $64,900^{\mathrm{b}}$ & $-15,0$ & $-10,0$ & $-36,0$ & $-11,0$ \\
\hline \multirow{2}{*}{ Sinapaldeído } & \multirow{2}{*}{5,64} & \multirow{2}{*}{206,942} & $177,000^{\mathrm{a}}$ & $-20,0$ & $-10,0$ & $-26,0$ & $-11,0$ \\
\hline & & & $148,900^{b}$ & $-20,0$ & $-10,0$ & $-34,0$ & $-9,0$ \\
\hline \multirow{2}{*}{ Ácido sinápico } & \multirow{2}{*}{5,13} & & $163,900^{\mathrm{a}}$ & $-120,0$ & $-10,0$ & $-20,0$ & $-9,0$ \\
\hline & & & $192,900^{\mathrm{b}}$ & $-120,0$ & $-10,0$ & $-28,0$ & $-11,0$ \\
\hline Ácido y & $63+35+3$ & 166 & $137,000^{\mathrm{a}}$ & $-140,0$ & $-10,0$ & $-12,0$ & $-9,0$ \\
\hline FAluo & & 100 & 109 & $-140,0$ & $-10,0$ & $-16,0$ & $-7,0$ \\
\hline $\begin{array}{l}\text { Composto } \\
\text { fenólico }\end{array}$ & $\begin{array}{l}\text { Tempo } \\
\text { de } \\
\text { retenção } \\
\text { (min) }\end{array}$ & $\begin{array}{c}\text { Íon } \\
\text { precursor } \\
{[\mathbf{M}+\mathbf{H}]^{+}}\end{array}$ & $\begin{array}{l}\text { Fragmentos } \\
\qquad(\mathrm{m} / \mathrm{z})\end{array}$ & $\begin{array}{l}\text { DP } \\
\text { (V) }\end{array}$ & $\begin{array}{l}\text { EP } \\
\text { (V) }\end{array}$ & CE $(V)$ & $\begin{array}{c}\text { CXP } \\
(\mathbf{V})\end{array}$ \\
\hline Ácido $p$ - & 3,05 & 59 & 77,0 & 56,0 & $-10,0$ & 29,0 & 10,0 \\
\hline o & & & 94,00 & 5,0 & 0,0 & 19,0 & 8,0 \\
\hline Apigenina & 6.73 & 270,953 & 153,0 & 181,0 & $-10,0$ & 41,0 & 10,0 \\
\hline Артуспाшіа & 0,15 & 210,9035 & 90,90 & 181,0 & $-10,0$ & 49,0 & 14,0 \\
\hline Ácido benzoico & 5,83 & 122,936 & $79,000^{\mathrm{a}}$ & 36,0 & $-10,0$ & 17,0 & 12,0 \\
\hline & & & 51,00 & 36,0 & $-10,0$ & 51,0 & 24,0 \\
\hline Catequina & 3,82 & 291.002 & $139,000^{\mathrm{a}}$ & 16,0 & $-10,0$ & 21,0 & 10,0 \\
\hline & 02 & 291,002 & $123,000^{\mathrm{b}}$ & 16,0 & $-10,0$ & 19,0 & 8,0 \\
\hline Ácido clorogênico & 3,76 & 355,058 & $163,000^{\mathrm{a}}$ & 46,0 & $-10,0$ & 21,0 & 10,0 \\
\hline & & & 89,00 & 46,0 & $-10,0$ & 75,0 & 14,0 \\
\hline (-)-Epicatequina & 4,27 & 291,002 & $138,900^{\text {a }}$ & 36,0 & $-10,0$ & 21,0 & 8,0 \\
\hline & 4,21 & & $123,000^{b}$ & 36,0 & $-10,0$ & 21,0 & 8,0 \\
\hline Ácido ferúlico & 5,20 & 194,987 & $176,900^{\text {a }}$ & 21,0 & $-10,0$ & 11,0 & 10,0 \\
\hline & & & 89,00 & 21,0 & $-10,0$ & 41,0 & 10,0 \\
\hline Galangina & 13 & 270,953 & $153,000^{\mathrm{a}}$ & 176,0 & $-10,0$ & 43,0 & 10,0 \\
\hline & & & 115,10 & 176,0 & $-10,0$ & 59,0 & 8,0 \\
\hline Hesperidina & & 6 & $303,000^{\mathrm{a}}$ & 51,0 & $-10,0$ & 31,0 & 16,0 \\
\hline Hesperiuma & J, & 8 & $153,100^{b}$ & 51,0 & $-10,0$ & 67,0 & 10,0 \\
\hline
\end{tabular}

Revista do Congresso Sul Brasileiro de Engenharia de Alimentos 
Recebido em:

$01 / 09 / 2018$

Aceito em:

$14 / 11 / 2018$

\begin{tabular}{|c|c|c|c|c|c|c|c|}
\hline \multirow{2}{*}{ Kaempferol } & \multirow{2}{*}{6,85} & \multirow{2}{*}{286,926} & $153,000^{\mathrm{a}}$ & 111,0 & $-10,0$ & 43,0 & 10,0 \\
\hline & & & $68,900^{\mathrm{b}}$ & 111,0 & $-10,0$ & 89,0 & 10,0 \\
\hline \multirow{2}{*}{ Luteolina } & \multirow{2}{*}{6,24} & \multirow{2}{*}{286,926} & $153,000^{\mathrm{a}}$ & 111,0 & $-10,0$ & 43,0 & 10,0 \\
\hline & & & $68,900^{\mathrm{b}}$ & 111,0 & $-10,0$ & 89,0 & 10,0 \\
\hline \multirow{2}{*}{ Pinocembrin } & \multirow[b]{2}{*}{8,10} & \multirow{2}{*}{257,025} & $153,000^{\mathrm{a}}$ & 96,0 & $-10,0$ & 33,0 & 10,0 \\
\hline & & & $76,900^{b}$ & 96,0 & $-10,0$ & 73,0 & 10,0 \\
\hline \multirow{2}{*}{ Siringaldeído } & \multirow{2}{*}{5,07} & \multirow{2}{*}{183,008} & $123,100^{\mathrm{a}}$ & 41,0 & $-10,0$ & 17,0 & 8,0 \\
\hline & & & $77,000^{b}$ & 41,0 & $-10,0$ & 31,0 & 10,0 \\
\hline \multirow{2}{*}{ Ácido siríngico } & \multirow{2}{*}{4,30} & \multirow{2}{*}{199,018} & $140,000^{a}$ & 16,0 & $-10,0$ & 21,0 & 10,0 \\
\hline & & & $155,100^{b}$ & 16,0 & $-10,0$ & 13,0 & 10,0 \\
\hline
\end{tabular}

Fonte: Adaptado de Seraglio et al. (2018). Legenda: DP, potencial de agrupamento (do inglês, declustering potential); EP, potencial de entrada (do inglês, entrance potential); CE, energia de colisão (do inglês, collision energy); CXP, potencial de saída da célula de colisão (do inglês, collision cell exit potential); ${ }^{a}$ íon de quantificação; ${ }^{b}$ íon de confirmação.

Tabela 2 - Faixa linear, $\mathrm{R}^{2}$ e limites de detecção (LD) e quantificação (LQ).

\begin{tabular}{lcccc}
\hline Compostos fenólicos & $\begin{array}{c}\text { Faixa linear } \\
\left(\boldsymbol{\mu g} \mathbf{~ L}^{-\mathbf{1}}\right)^{\mathbf{1}}\end{array}$ & $\mathbf{R}^{\mathbf{2} *}$ & $\mathbf{L D}\left(\boldsymbol{\mu g} \mathbf{~ L}^{-\mathbf{1}}\right)^{\mathbf{1}}$ & $\mathbf{L Q}\left(\boldsymbol{\mu g} \mathbf{~ L}^{-\mathbf{1}}\right)^{\mathbf{1}}$ \\
\hline Ácido 3,4-dihidroxibenzoico & $0,8-225,0$ & 0,993 & 0,40 & 0,80 \\
Ácido benzoico & $12,8-250,0$ & 0,988 & 3,20 & 12,80 \\
Ácido cafeico & $3,2-20,9$ & 0,997 & 1,60 & 3,20 \\
Ácido clorogênico & $0,4-25,0$ & 0,990 & 0,10 & 0,40 \\
Ácido ferúlico & $3,2-25,0$ & 0,996 & 1,60 & 3,20 \\
Ácido gálico & $1,6-25,0$ & 0,988 & 0,80 & 1,60 \\
Ácido -aminobenzóico & $1,6-20,9$ & 0,988 & 0,20 & 1,60 \\
Ácido p-cumárico & $0,8-25,0$ & 0,987 & 0,20 & 0,80 \\
Ácido salić́lico & $3,2-225,0$ & 0,992 & 0,20 & 3,20 \\
Ácido sinápico & $0,8-25,0$ & 0,990 & 0,20 & 0,80 \\
Ácido siríngico & $1,6-25,0$ & 0,997 & 0,80 & 1,60 \\
Ácido vanílico & $0,4-25,0$ & 0,994 & 0,20 & 0,40 \\
Apigenina & $0,8-25,0$ & 0,998 & 0,20 & 0,80 \\
(+)-Catequina & $1,6-25,0$ & 0,994 & 0,40 & 1,60 \\
Coniferaldeído & $1,6-25,0$ & 0,990 & 0,20 & 1,60 \\
Crisina & $0,8-20,9$ & 0,997 & 0,20 & 0,80 \\
(-)-Epicatequina & $1,6-25,0$ & 0,994 & 0,40 & 1,60 \\
(-)-Epigalocatequina galato & $0,8-20,9$ & 0,992 & 0,03 & 0,80 \\
& & & &
\end{tabular}




\section{Recebido em:}

$01 / 09 / 2018$

Aceito em:

$14 / 11 / 2018$

\begin{tabular}{lcccc} 
Galangina & $1,6-25,0$ & 0,993 & 0,20 & 1,60 \\
Hesperidina & $0,4-25,0$ & 0,990 & 0,20 & 0,40 \\
Isoquercitrina & $0,8-25,0$ & 0,998 & 0,10 & 0,80 \\
Isoramnetina & $0,5-26,1$ & 0,992 & 0,13 & 0,50 \\
Kaempferol & $1,6-25,0$ & 0,989 & 0,20 & 1,60 \\
Luteolina & $0,4-25,0$ & 0,991 & 0,20 & 0,40 \\
4-Metilumbeliferona & $0,8-25,0$ & 0,988 & 0,20 & 0,80 \\
Naringenina & $0,2-20,9$ & 0,991 & 0,10 & 0,20 \\
Naringina & $0,8-25,0$ & 0,995 & 0,05 & 0,80 \\
Pinobanksin & $0,5-28,7$ & 0,993 & 0,03 & 0,50 \\
Pinocembrin & $0,4-25,0$ & 0,998 & 0,20 & 0,40 \\
Quercetina & $0,8-25,0$ & 0,991 & 0,05 & 0,80 \\
Rutina & $0,4-25,0$ & 0,993 & 0,10 & 0,40 \\
Sinapaldeído & $0,4-25,0$ & 0,991 & 0,20 & 0,40 \\
Siringaldeído & $1,6-20,9$ & 0,995 & 0,40 & 1,60 \\
\hline Fonte ${ }^{1}$ Adaptado de Seraglio et al. (2018) * Elaborado pelos autores (2018). &
\end{tabular}

Fonte: ${ }^{1}$ Adaptado de Seraglio et al. (2018). * Elaborado pelos autores (2018).

\subsection{Determinação da capacidade antioxidante in vitro}

Extração dos compostos com capacidade antioxidante

A extração dos compostos com capacidade antioxidante foi realizada de acordo com o método proposto por Rufino et al. (2010), com adaptações (SERAGLIO et al., 2018). Inicialmente, $2,0 \mathrm{~g}( \pm 0,1)$ de amostra triturada foram submetidas à extração com $4 \mathrm{~mL}$ de metanol:água $(1: 1, \mathrm{v} / \mathrm{v})$ em banho ultrassom por $30 \mathrm{~min}$ seguida de centrifugação por $10 \mathrm{~min}$ a $1338 \mathrm{~g}$. O sobrenadante foi transferido para um balão volumétrico de $10 \mathrm{~mL}$. O resíduo foi extraído com $4 \mathrm{~mL}$ de acetona:água (7:3, v/v) em banho ultrassom por 30 min. Após centrifugação, o sobrenadante foi transferido para o mesmo balão volumétrico e este completado com água ultrapura.

Determinação da capacidade antioxidante in vitro

A capacidade antioxidante in vitro dos extratos das frutas foi avaliada pelos métodos de sequestro do radical 2,2-difenil-1-picrilhidrazil (DPPH) e pelo poder redutor do ferro (FRAP).

O ensaio DPPH foi realizado de acordo com o método de Brand-Williams, Cuvelier e Berset (1995), com adaptações (KIM et al., 2002). Uma alíquota de $2,9 \mathrm{~mL}$ de solução de DPPH $(0,1 \mathrm{mmol} \mathrm{L}-$ ${ }^{1} \mathrm{em}$ metanol $80 \%, \mathrm{v} / \mathrm{v}$ ) foi misturada com $0,1 \mathrm{~mL}$ do extrato das frutas em diluição adequada. A mistura foi agitada e deixada por 30 min no escuro em temperatura ambiente. A absorvância da solução de DPPH antes e após a adição do extrato foi determinada em $515 \mathrm{~nm}$ (espectrofotômetro UV-Vis, Spectro Vision 


\section{Recebido em:}

$01 / 09 / 2018$

Aceito em:

$14 / 11 / 2018$

SB 1810-60 S, Beijing, China). A capacidade antioxidante dos extratos das frutas foi calculada como percentagem de inibição e expressa em mg Trolox $100 \mathrm{~g}^{-1} \mathrm{em}$ matéria seca.

O ensaio FRAP foi determinado conforme método descrito por Benzie e Strain (1996), com adaptações (ARNOUS; MAKRIS; KEFALAS, 2002). Uma alíquota dos extratos das frutas em diluição adequada $(200 \mu \mathrm{L})$ foi misturada com $200 \mu \mathrm{L}$ de $\mathrm{FeCl}_{3}\left(3 \mathrm{mmol} \mathrm{L}^{-1} \mathrm{em} 5 \mathrm{~mol} \mathrm{~L}^{-1}\right.$ de ácido cítrico) em um tubo de polipropileno e deixado em banho de água a $37 \pm 2{ }^{\circ} \mathrm{C}$ por $30 \mathrm{~min}$. Na sequência, $3,6 \mathrm{~mL}$ de solução TPTZ $\left(0,312 \mathrm{mg} \mathrm{mL}^{-1} \mathrm{em} 0,05 \mathrm{~mol} \mathrm{~L}^{-1} \mathrm{de} \mathrm{HCl}\right)$ foi adicionada à mistura e agitada manualmente. Após $10 \mathrm{~min}$, a absorvância da mistura foi determinada em $620 \mathrm{~nm}$. A capacidade antioxidante dos extratos das frutas foi expressa em $\mu \mathrm{mol}$ Trolox $100 \mathrm{~g}^{-1} \mathrm{em}$ matéria seca.

\subsection{Análise estatística}

As análises foram realizadas em triplicatas independentes $(n=3)$. Os dados foram expressos como média \pm desvio padrão e analisados por meio do software Statistica 13.0 (Statsoft Inc., Tulsa, OK, E.U.A). Análise de variância e teste de Tukey foram realizados buscando identificar diferenças estatísticas $(p<0,05)$ entre as médias dos diferentes estádios de maturação. Análises de correlação de Pearson foram realizadas para avaliar associações entre os compostos fenólicos e a capacidade antioxidante.

\section{RESULTADOS E DISCUSSÃO}

\subsection{Compostos fenólicos}

Os compostos fenólicos investigados nos três estádios de maturação da acerola (Malpighia emarginata DC.) estão apresentados na Tabela 3. Considerando todos os estádios avaliados, foram quantificados 16 compostos: 8 flavonoides (catequina, isoquercitrina, isoramnetina, kempferol, luteolina, naringenina, pinobanksin e quercetina), 7 ácidos fenólicos (ácidos cafeico, $p$-cumárico, 3,4dihidroxibenzoico, ferúlico, gálico, salicílico e sinápico) e 1 aldeído derivado da lignina (sinapaldeído).

Tabela 3 - Compostos fenólicos ( $\mathrm{mg} \mathrm{kg}^{-1} \mathrm{em}$ matéria seca) da acerola (Malpighia emarginata DC.) durante a maturação.

\begin{tabular}{lccc}
\hline Composto fenólico & Estádio 1 & Estádio 2 & Estádio 3 \\
\hline $\begin{array}{l}\text { Cumarinas } \\
\text { 4-metilumbeliferona }\end{array}$ & $<\mathrm{LD}$ & $<\mathrm{LD}$ & $<\mathrm{LD}$ \\
Flavonoides & & & \\
Apigenina & $<\mathrm{LQ}$ & $<\mathrm{LQ}$ & $<\mathrm{LQ}$ \\
(+)-Catequina & $0,49 \pm 0,01^{\text {a }}$ & $0,28 \pm 0,01^{\mathrm{b}}$ & $<\mathrm{LQ}$ \\
Crisina & $<\mathrm{LD}$ & $<\mathrm{LD}$ & $<\mathrm{LD}$ \\
(+)-Epicatequina & $<\mathrm{LQ}$ & $<\mathrm{LD}$ & $<\mathrm{LD}$ \\
(-)-Epigalocatequina galato & $<\mathrm{LD}$ & $<\mathrm{LD}$ & $<\mathrm{LD}$ \\
Galangina & $<\mathrm{LD}$ & $<\mathrm{LD}$ & $<\mathrm{LD}$ \\
\hline
\end{tabular}


Recebido em:

$01 / 09 / 2018$

Aceito em:

$14 / 11 / 2018$

\begin{tabular}{|c|c|c|c|}
\hline Hesperidina & $<\mathrm{LD}$ & $<\mathrm{LD}$ & $<\mathrm{LD}$ \\
\hline Isoquercitrina & $19,11 \pm 1,51^{b}$ & $36,66 \pm 1,09^{\mathrm{a}}$ & $18,33 \pm 0,63^{b}$ \\
\hline Isoramnetina & $36,95 \pm 0,95^{b}$ & $43,90 \pm 0,29^{a}$ & $26,26 \pm 0,20^{c}$ \\
\hline Kaempferol & $36,53 \pm 2,45^{\mathrm{a}}$ & $48,42 \pm 5,98^{a}$ & $52,89 \pm 2,20^{\mathrm{a}}$ \\
\hline Luteolina & $0,09 \pm 0,01^{b}$ & $0,09 \pm 0,001^{\mathrm{b}}$ & $0,18 \pm 0,01^{\mathrm{a}}$ \\
\hline Naringenina & $0,40 \pm 0,02^{\mathrm{c}}$ & $0,55 \pm 0,03^{\mathrm{b}}$ & $0,73 \pm 0,05^{\mathrm{a}}$ \\
\hline Naringina & $<\mathrm{LQ}$ & $<\mathrm{LQ}$ & $<\mathrm{LD}$ \\
\hline Pinobanksin & $0,48 \pm 0,02^{b}$ & $0,66 \pm 0,07$ ab & $0,87 \pm 0,07^{\mathrm{a}}$ \\
\hline Pinocembrin & $<\mathrm{LD}$ & $<\mathrm{LD}$ & $<\mathrm{LD}$ \\
\hline Quercetina & $317,30 \pm 12,70^{b}$ & $358,10 \pm 0,40^{\mathrm{a}}$ & $312,95 \pm 2,47^{b}$ \\
\hline Rutina & $<\mathrm{LD}$ & $<\mathrm{LD}$ & $<\mathrm{LD}$ \\
\hline \multicolumn{4}{|l|}{ Aldeídos derivados da lignina } \\
\hline Coniferaldeído & $<\mathrm{LQ}$ & $<\mathrm{LQ}$ & $<\mathrm{LQ}$ \\
\hline Sinapaldeído & $<\mathrm{LD}$ & $<\mathrm{LQ}$ & $0,07 \pm 0,002$ \\
\hline Siringaldeído & $<\mathrm{LQ}$ & $<\mathrm{LQ}$ & $<\mathrm{LQ}$ \\
\hline \multicolumn{4}{|l|}{ Ácidos fenólicos } \\
\hline Ácido $p$-aminobenzóico & $<\mathrm{LQ}$ & $<\mathrm{LQ}$ & $<\mathrm{LQ}$ \\
\hline Ácido benzoico & $<\mathrm{LQ}$ & $<\mathrm{LQ}$ & $<\mathrm{LQ}$ \\
\hline Ácido cafeico & $291,00 \pm 20,20^{\mathrm{a}}$ & $276,21 \pm 5,20^{a}$ & $2,94 \pm 0,41^{\mathrm{b}}$ \\
\hline Ácido clorogênico & $<\mathrm{LQ}$ & $<\mathrm{LQ}$ & $<\mathrm{LQ}$ \\
\hline Ácido $p$-cumárico & $9,22 \pm 0,91^{\mathrm{a}}$ & $9,50 \pm 0,50^{\text {a }}$ & $6,13 \pm 0,38^{b}$ \\
\hline Ácido 3,4-dihidroxibenzoico & $3,89 \pm 0,35^{b}$ & $5,07 \pm 0,61^{a b}$ & $5,99 \pm 0,50^{\mathrm{a}}$ \\
\hline Ácido ferúlico & $11,61 \pm 1,49^{\mathrm{a}}$ & $12,41 \pm 1,09^{\mathrm{a}}$ & $5,25 \pm 0,29^{b}$ \\
\hline Ácido gálico & $1,54 \pm 0,03^{\text {a }}$ & $1,42 \pm 0,03^{\text {a }}$ & $1,12 \pm 0,06^{\mathrm{b}}$ \\
\hline Ácido salicílico & $<\mathrm{LD}$ & $1,09 \pm 0,07^{\mathrm{a}}$ & $1,17 \pm 0,09^{\mathrm{a}}$ \\
\hline Ácido sinápico & $0,37 \pm 0,03^{a}$ & $0,38 \pm 0,05^{\mathrm{a}}$ & $0,38 \pm 0,05^{\mathrm{a}}$ \\
\hline Ácido siríngico & $<\mathrm{LQ}$ & $<\mathrm{LQ}$ & $<\mathrm{LQ}$ \\
\hline Ácido vanílico & $<\mathrm{LD}$ & $<\mathrm{LD}$ & $<\mathrm{LD}$ \\
\hline $\begin{array}{l}\text { Soma dos fenólicos } \\
\text { quantificados }\end{array}$ & 728,98 & 794,74 & 435,26 \\
\hline
\end{tabular}

Fonte: Elaborado pelos autores (2018). Legenda: ${ }^{\text {a-c }}$ Letras diferentes na mesma linha indicam diferença estatística significativa $(p<0,05)$ entre as médias de acordo com o teste de Tukey. LD - Limite de detecção. LQ - Limite de quantificação.

Considerando todos os estádios avaliados, os compostos majoritários foram a quercetina (312,95 a 358,10 mg kg${ }^{-1}$ em matéria seca), o ácido cafeico (2,94 a 291,00 $\mathrm{mg} \mathrm{kg}^{-1} \mathrm{em}$ matéria seca), o kaempferol (36,53 a 52,89 $\mathrm{mg} \mathrm{kg}^{-1} \mathrm{em}$ matéria seca) e a isoramnetina (26,26 a 43,90 mg kg-1 em matéria seca). Os demais compostos quantificados apresentaram a seguinte ordem de concentração: isoquercitrina > ácido ferúlico > ácido $p$-cumárico > ácido 3,4-dihidrocibenzoico > ácido gálico > ácido 


\section{Recebido em:}

$01 / 09 / 2018$

Aceito em:

$14 / 11 / 2018$

salicílico $>$ pinobanksin $>$ naringenina $>$ catequina $>$ ácido sinápico $>$ luteolina $>$ sinapaldeído (Tabela $3)$. Os resultados encontrados no presente estudo foram superiores aos encontrados por Bataglion et al. (2015) para os compostos quercetina (27,73 mg kg-1 em matéria seca), kaempferol (14,26 mg kg-1 em matéria seca), ácido cafeico $\left(5,33 \mathrm{mg} \mathrm{kg}^{-1} \mathrm{em}\right.$ matéria seca) e ácido ferúlico $\left(5,16 \mathrm{mg} \mathrm{kg}^{-1} \mathrm{em}^{-}\right.$matéria seca) e inferiores para luteolina $\left(3,16 \mathrm{mg} \mathrm{kg}^{-1} \mathrm{em}\right.$ matéria seca) e ácido $p$-cumárico $\left(11,36 \mathrm{mg} \mathrm{kg}^{-1} \mathrm{em}\right.$ matéria seca). Também foi observado neste estudo, valores de maneira geral superiores aos reportados por Oliveira et al. (2012) para quercetina (62,3 a 334,9 $\mathrm{mg} \mathrm{kg}^{-1} \mathrm{em}$ matéria seca). No estudo realizado por Nascimento et al. (2018), os compostos rutina, quercetina, epicatequina, ácido cafeico e ácido gálico foram os compostos majoritários encontrados em frutos de acerola. Estas diferenças podem estar associadas a diversos fatores como gênero, espécie, cultivar, grau de maturação, clima, solo (LEE; DOSSETT; FINN, 2012). As concentrações de compostos fenólicos encontrados para acerola foram de maneira geral superiores aos encontrados para outras frutas como carambola $\left(580,00 \mathrm{mg} \mathrm{kg}^{-1} \mathrm{em}\right.$ matéria seca), graviola (309,00 mg kg-1 em matéria seca), araçá-boi (169,00 mg kg-1 em matéria seca) e buriti (96 mg kg-1 em matéria seca) (GONÇALVES; LAJOLO; GENOVESE, 2010).

Ao analisar as concentrações dos compostos quantificados nos três estádios avaliados, observou-se que os valores variaram ao longo da maturação, com exceção do kaempferol e do ácido sinápico, os quais não apresentaram diferença estatística significativa $(p<0,05)$ durante a maturação (Tabela 3). Compostos como a luteolina $\left(0,18 \mathrm{mg} \mathrm{kg}^{-1}\right)$, a naringenina $\left(0,73 \mathrm{mg} \mathrm{kg}^{-1}\right)$, o sinapaldeído (0,07 mg kg-1), o ácido 3,4-dihidroxibenzoico (5,99 $\left.\mathrm{mg} \mathrm{kg}^{-1}\right)$ apresentaram maiores concentrações nos frutos mais maduros (estádio 3$)$, enquanto que compostos como a catequina $(<\mathrm{LQ})$, isoramnetina $(26,26$ $\left.\mathrm{mg} \mathrm{kg}{ }^{-1}\right)$, ácido cafeico $\left(2,94 \mathrm{mg} \mathrm{kg}^{-1}\right)$, ácido $p$-cumárico $\left(6,13 \mathrm{mg} \mathrm{kg}^{-1}\right)$, ácido ferúlico $\left(5,25 \mathrm{mg} \mathrm{kg}^{-1}\right)$ e ácido gálico $\left(1,12 \mathrm{mg} \mathrm{kg}^{-1}\right)$ apresentaram os menores valores neste estádio. $\mathrm{O}$ estádio 3 também apresentou o menor valor de soma dos fenólicos quantificados, demonstrando que, de maneira geral, ocorreu uma diminuição nos teores de compostos fenólicos com o avanço da maturação. Em estudos que avaliaram o teor de compostos fenólicos na acerola em diferentes estádios de maturação, também foi encontrado uma tendência de diminuição desses compostos no decorrer da maturação (LIMA et al., 2005; OLIVEIRA et al., 2012; RIGHETTO; NETTO; CARRARO, 2005). O mesmo comportamento foi encontrado para diferentes frutas como para a maior parte das cultivares de morango (AABY et al., 2012), açaí (GORDON et al., 2012), nêspera (DING et al., 2001), guabiju, jabuticaba e jambolão (SERAGLIO et al., 2018).

No decorrer da maturação dos frutos, os compostos fenólicos sofrem vários processos de biossíntese, levando a mudanças na sua composição (PRASANNA; PRABHA; THARANATHAN, 2007), o que vem de encontro aos resultados obtidos nesse estudo. A redução dos compostos -fenólicos pode ser atribuída a oxidação dos polifenóis pela enzima polifenoloxidase durante a maturação dos frutos (FAWOLE; OPARA, 2013) e também pode estar relacionada à diminuição no metabolismo primário dos frutos maduros, resultando na falta de substratos, os quais são essenciais para a biossíntese dos compostos fenólicos (GRUZ et al., 2011). Além disso, os teores de compostos fenólicos podem variar de acordo com a região de plantio, tipo de solo, exposição solar, índice pluviométrico, cultivar e estádio de maturação (MARTINS et al., 2011).

\subsection{Capacidade antioxidante}

A capacidade antioxidante das amostras de acerola foi avaliada pelos métodos de sequestro do 


\section{Recebido em:}

$01 / 09 / 2018$

Aceito em:

$14 / 11 / 2018$

radical 2,2-difenil-1-picrilhidrazil (DPPH) e pelo poder redutor do ferro (FRAP) e os resultados estão apresentados na Tabela 4 .

Tabela 4 - Capacidade antioxidante da acerola (Malpighia emarginata DC.) durante a maturação.

\begin{tabular}{lccc}
\hline Capacidade antioxidante & Estádio 1 & Estádio 2 & Estádio 3 \\
\hline DPPH $^{*}$ & $1117,71 \pm 6,01^{\mathrm{a}}$ & $1120,40 \pm 10,76^{\mathrm{a}}$ & $963,26 \pm 12,00^{\mathrm{b}}$ \\
FRAP $^{* *}$ & $400,87 \pm 3,34^{\mathrm{b}}$ & $508,24 \pm 11,09^{\mathrm{a}}$ & $341,19 \pm 5,23^{\mathrm{c}}$ \\
\hline
\end{tabular}

Fonte: Elaborado pelos autores (2018). Legenda: ${ }^{*} \mathrm{mg}$ Trolox $\mathrm{g}^{-1} \mathrm{em}$ matéria seca; $* * \mu \mathrm{mol}$ Trolox $\mathrm{g}^{-1}$ em matéria seca. ${ }^{\mathrm{a}-\mathrm{c}}$ Letras diferentes na mesma linha indicam diferença estatística significativa $(p<0,05)$ entre as médias de acordo com o teste de Tukey.

A acerola apresentou valores elevados tanto para o ensaio DPPH (963,23 a 1120,40 mg Trolox $\mathrm{g}^{-1}$ em matéria seca) quanto para o ensaio FRAP (341,19 a 508,24 $\mu$ mol Trolox g ${ }^{-1}$ em matéria seca). O elevado potencial antioxidante da acerola já é reconhecido na literatura, onde valores superiores de capacidade antioxidante frente a outros frutos como juçara, jabuticaba, jambolão, murta, uvaia, bacuri, durian já foram reportados (RUFINO et al., 2010; ANANTACHOKE et al., 2016). Os valores encontrados neste estudo para acerola pelo método DPPH foram superiores em relação aos frutos brasileiros tucumã $\left(123,00 \mu \mathrm{mol}\right.$ Trolox $\mathrm{g}^{-1} \mathrm{em}$ matéria seca), cambuci $\left(135,00 \mu \mathrm{mol}\right.$ Trolox g $\mathrm{e}^{-1} \mathrm{em}$ matéria seca), bacuri, araçá (15,00 $\mu \mathrm{mol}$ Trolox $\mathrm{g}^{-1}$ em matéria seca), cupuaçu $\left(18,00 \mu \mathrm{mol}\right.$ Trolox g $\mathrm{g}^{-1}$ em matéria seca), carambola $\left(57,00 \mu \mathrm{mol}\right.$ Trolox $\mathrm{g}^{-1}$ em matéria seca), graviola $\left(27,00 \mu \mathrm{mol}\right.$ Trolox $\mathrm{g}^{-}$ ${ }^{1}$ em matéria seca) (GONÇALVES; LAJOLO; GENOVESE, 2010) e inferiores em relação ao abacaxi $\left(1260,00 \mu \mathrm{mol}\right.$ Trolox $\mathrm{g}^{-1}$ em matéria seca) e tamarindo $\left(3310,00 \mu \mathrm{mol}\right.$ Trolox $\mathrm{g}^{-1}$ em matéria seca) (PAZ et al., 2015). Segundo Righetto, Netto, Carraro (2005), a capacidade antioxidante da acerola é construída sobre a ação complementar de seus diferentes componentes, ao invés da ação independente de cada composto individual. Portanto, a capacidade antioxidante depende da ação sinérgica dos constituintes das diferentes frações de compostos, os quais se destacam os compostos fenólicos e a vitamina C (NASCIMENTO et al., 2018; RIGHETTO; NETTO; CARRARO, 2005).

Ao comparar os resultados durante o ciclo de maturação, observou-se diferença estatística significativa $(p<0,05)$ entre os estádios de maturação avaliados. Tanto para o ensaio DPPH, quanto para o ensaio FRAP foi observado menor capacidade antioxidante no estádio 3 (Tabela 4). A tendência de diminuição na capacidade antioxidante ao longo do amadurecimento da acerola avaliada por diferentes métodos também foi reportada por Oliveira et al. (2012), Nascimento et al. (2018), Delva e Schneider (2013b) e Gruz et al. (2011), sugerindo a ocorrência de um decréscimo no teor de antioxidantes naturais neste fruto com o avanço da maturação (GRUZ et al., 2011).

A análise de correlação de Pearson $(r)$ realizada entre os compostos fenólicos individuais avaliados e os resultados de capacidade antioxidante mostrou que para o FRAP, a isoramnetina $(r=$ $0,9639 ; p=0,0019)$, a quercetina $(r=0,9115 ; p=0,0011)$ e a isoquercitrina $(r=0,9210 ; p=0,0091)$ apresentaram correlação positiva e significativa. Em contrapartida, para o DPPH tiveram correlação negativa e significativa a luteolina $(r=-0,9989 ; p=0,00002)$, a naringenina $(r=-0,8769 ; p=0,0218)$ e o pinobanksin $(r=-0,8539 ; p=0,0304)$, enquanto que apresentaram correlação significativa e positiva os seguintes compostos: catequina $(r=0,8892 ; p=0,0177)$, ácido ferúlico $(r=0,9627 ; p=0,0021)$, ácido $p$-cumárico $(r=0,9487 ; p=0,0039)$, ácido gálico $(r=0,9382 ; p=0,0056)$, e ácido cafeico $(r=$ 0,9933; $p=0,00007)$. Esses dados sugerem que os compostos fenólicos majoritários identificados nesse 


\section{Recebido em:}

$01 / 09 / 2018$

Aceito em:

$14 / 11 / 2018$

estudo podem contribuir para a alta capacidade antioxidante nos frutos acerola nos dois métodos aplicados.

\section{CONCLUSÃO}

Dentre os 33 compostos fenólicos investigados, foram quantificados 16 compostos, sendo a quercetina, ácido cafeico, kaempferol e isoramnetina os principais fenólicos encontrados neste fruto. Ainda, valores elevados de capacidade antioxidante foram observados nos estádios investigados.

$\mathrm{O}$ processo de maturação influenciou significativamente a concentração da maioria dos fenólicos investigados bem como a capacidade antioxidante nos frutos de acerola. De maneira geral, uma tendência de diminuição nos teores de compostos fenólicos e da capacidade antioxidante com o avanço da maturação foi observado. Contudo, os teores de compostos fenólicos e capacidade antioxidante nos três estádios avaliados nos frutos de acerola podem ser considerados expressivos, podendo estes contribuir com a ingestão diária de antioxidante naturais.

\section{REFERÊNCIAS}

AABY, K. et al. Phenolic compounds in strawberry (Fragaria x ananassa Duch.) fruits: composition in 27 cultivars and changes during ripening. Food Chemistry, v. 132, p. 86-97, 2012.

AHMAD, N. et al. Characterization of free and conjugated phenolic compounds in fruits of selected wild plants. Food Chemistry, v. 190, p. 80-89, 2016.

ANANTACHOKE, N. et al. Thai fruits exhibit antioxidant activity and induction of antioxidant enzymes in HEK-293 cells. Evidence-Based Complementary and Alternative Medicine, v. 2016, p. 1-14, 2016.

ARNOUS, A.; MAKRIS, D. P.; KEFALAS, P. Correlation of pigment and flavanol content with antioxidant properties in selected aged regional wines from Greece. Journal of Food Composition and Analysis, v. 15, n. 6, p. 655-665, 2002.

BARBOZA, S. B. S. C.; TAVARES, E. D.; MELO, M. B. de. Instruções para o cultivo da acerola. Aracaju: EMBRAPA-CPATC, 1996. 42p. (EMBRAPA-CPATC. Circular Técnica. 6).

BATAGLION, G. A. et al. Determination of the phenolic composition from Brazilian tropical fruits by UHPLC-MS/MS. Food Chemistry, v.180, p.280-287, 2015.

BENZIE, I. F. F.; STRAIN, J. J. The ferric reducing ability of plasma (FRAP) as a measure of antioxidant power: the FRAP assay. Analytical Biochemistry, v. 239, p. 70-76, 1996.

BOEING, J. S. et al. Evaluation of solvent effect on the extraction of phenolic compounds and antioxidant capacities from the berries: application of principal component analysis. Chemistry Central Journal, v. 8, n. 1, p. 48, 2014. 
BRAND-WILLIAMS, W.; CUVELIER, M. E.; BERSET, C. Use of a free radical method to evaluate antioxidant activity. LWT - Food Science and Technology, v. 28, n. 1, p. 25-30, 1995.

DE ASSIS, S. A. et al. Antioxidant activity, ascorbic acid and total phenol of exotic fruits occurring in Brazil. International journal of food sciences and nutrition, v. 60, n. 5, p. 439$48,2009$.

DE LA ROSA, L.; ALVAREZ-PARILLA, E.; GONZÁLEZ-AGUIAR, G.A. Fruit and vegetable phytochemicals. Wiley-Blackwell. 2010.

DE ROSSO, V. V. et al. Determination of anthocyanins from acerola (Malpighia emarginata DC.) and açai (Euterpe oleracea Mart.) by HPLC-PDA-MS/MS. Journal of Food Composition and Analysis, v. 21, n. 4, p. 291-299, 2008.

DELVA, L.; SCHNEIDER, R. G. Acerola (Malpighia emarginata DC): production, postharvest handling, nutrition, and biological activity. Food Reviews International, v. 29, n. 2, p. 107-126, 2013a.

DELVA, L.; SCHNEIDER, R. G. Antioxidant activity and antimicrobial properties of phenolic extracts from acerola (Malpighia emarginata DC) fruit. International Journal of Food Science and Technology, v. 48, p. 1048-1056, 2013 b.

DING, C.-K. et al. Metabolism of phenolic compounds during loquat fruit development. Journal of Agricultural and Food Chemistry, v. 49, p. 2883-2888, 2001.

FAWOLE, O. A.; OPARA, U. L. Changes in physical properties, chemical and elemental composition and antioxidant capacity of pomegranate (cv. Ruby) fruit at five maturity stages. Scientia Horticulturae, v. 150, p. 37-46, 2013.

GONÇALVES, A. E. de S. S.; LAJOLO, F. R.; GENOVESE, M. I. Chemical composition and antioxidant/antidiabetic potential of Brazilian native fruits and and commercial frozen pulps. Journal of Agricultural and Food Chemistry, v. 58, p. 4666-4674, 2010.

GORDON, A. et al. Chemical characterization and evaluation of antioxidant properties of açaí fruits (Euterpe oleraceae Mart.) during ripening. Food Chemistry, v. 133, p. 256-263, 2012.

GRUZ, J. et al. Phenolic acid content and radical scavenging activity of extracts from medlar (Mespilus germanica L.) fruit at different stages of ripening. Food Chemistry, v. 124, p. 271-277, 2011.

HURTADO-FERNANDEZ, E. et al. Merging a sensitive capillary electrophoresis-ultraviolet detection method with chemometric exploratory data analysis for the determination of phenolic 


\section{Recebido em:}

$01 / 09 / 2018$

Aceito em:

$14 / 11 / 2018$

acids and subsequent characterization of avocado fruit. Food Chemistry, v. 141, p. 3492-3503, 2013.

IOM. Dietary reference intakes for vitamin A, vitamin $\mathrm{K}$, arsenic, boron, chromium, copper, iodine, iron, manganese, molybdenum, nickel, silicon, vanadium, and zinc. Institute of Medicine. Washington: National Academy Press, 2001.

KIM, D. et al. Vitamin C equivalent antioxidant capacity (VCEAC) of phenolics phytochemicals. Journal of agricultural and food chemistry, v. 50, p. 3713-3717, 2002.

LEE, J.; DOSSETT, M.; FINN, C. E. Rubus fruit phenolic research: the good, the bad, and the confusing. Food Chemistry, v. 130, n. 4, p. 785-796, 2012.

LEFFA, D. D. et al. Corrective effects of acerola (Malpighia emarginata DC.) juice intake on biochemical and genotoxical parameters in mice fed on a high-fat diet. Mutation Research Fundamental and Molecular Mechanisms of Mutagenesis, v. 770, p. 144-152, 2014.

LIMA, V. L. A. G. et al. Total phenolic and carotenoid contents in acerola genotypes harvested at three ripening stages. Food Chemistry, v. 90, p. 565-568, 2005.

MARTINS, S. et al. Bioactive phenolic compounds: production and extraction by solid-state fermentation. A review. Biotechnology Advances, v. 29, p. 365-373, 2011.

MEMON, A. F. et al. Simultaneous determination of quercetin, rutin, naringin, and naringenin in different fruits by capillary zone electrophoresis. Food Analytical Methods, v. 10, p. 83-91, 2017.

MEZADRI, T. et al. Antioxidant compounds and antioxidant activity in acerola (Malpighia emarginata DC.) fruits and derivatives. Journal of Food Composition and Analysis, v. 21, n. 4, p. 282-290, 2008.

NASCIMENTO, E. M. M. et al. HPLC and in vitro evaluation of antioxidant properties of fruit from Malpighia glabra (Malpighiaceae) at different stages of maturation. Food and Chemical Toxicology, v. 119, p. 457-463, 2018.

NUNES, R. S. et al. Antigenotoxicity and antioxidant activity of acerola fruit (Malpighia glabra L.) at two stages of ripeness. Plant Foods for Human Nutrition, v. 66, n. 2, p. 129-135, 2011.

OLIVEIRA, L. S. et al. Antioxidant metabolism during fruit development of different acerola (Malpighia emarginata D.C) clones. Journal of Agricultural and Food Chemistry, v.60, p. 7957-7964, 2012.

PAZ, M. et al. Brazilian fruit pulps as functional foods and additives: evaluation of bioactive compounds. Food Chemistry, v. 172, p.462-468, 2015. 
PRASANNA, V.; PRABHA; T. N.; THARANATHAN; R. N. Fruit ripening phenomena - an overview. Critical Reviews in Food Science and Nutrition, v. 47, p. 1-19, 2007.

RIGHETTO, A. M.; NETTO F. M.; CARRARO, F. Chemical composition and antioxidant activity of juices from mature and immature acerola (Malpighia emarginata DC). Food Science and Technology International, v. 11, p. 315-321, 2005.

RUFINO, M. D. S. M. et al. Bioactive compounds and antioxidant capacities of 18 non-traditional tropical fruits from Brazil. Food Chemistry, v. 121, n. 4, p. 996-1002, 2010.

SCHULZ, M. et al. Chemical composition, bioactive compounds and antioxidant capacity of juçara fruit (Euterpe edulis Martius) during ripening. Food Research International, v. 77, p. 125-131, 2015.

SERAGLIO, S. K. T. et al. Nutritional and bioactive potential of Myrtaceae fruits during ripening. Food Chemistry, v. 239, p. 649-656, 2018.

TACO - Tabela Brasileira de Composição de Alimentos. 4. ed. Campinas: UNICAMP/NEPA, 2011. 161 p. Disponível em: <http://www.unicamp.br/nepa/taco/tabela.php?ativo=tabela $>$. Acesso em: 28 out. 2018. 